Received: 7 November 2018

Revised: 13 November 2018

Accepted: 30 November 2018

Published: 30 December 2018

\title{
Analisis Survival dengan Model Regresi pada Data Tersensor Berdistribusi Log-logistik
}

\author{
Gatri Eka Kusumawardhani ${ }^{1, \text { a) }}$, Suyono ${ }^{2, \text { b) }}$, Vera Maya Santi ${ }^{2, c)}$

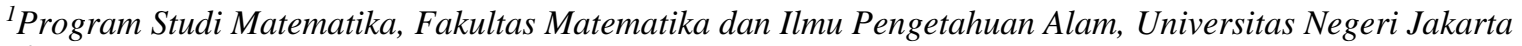 \\ ${ }^{2}$ Program Studi Statistika, Fakultas Matematika dan Ilmu Pengetahuan Alam, Universitas Negeri Jakarta \\ Email: ${ }^{\text {a) }}$ gatrieka82@gmail.com, ${ }^{\text {b) }}$ synjkt@yahoo.com, ${ }^{\mathrm{c})}$ vera.indr4@gmail.com
}

\begin{abstract}
Survival analysis is an analysis used to determine the length of time required by an object in order to survive. That time is influenced by several factors called independent variables. One way to know relationship is through a regression model. The dependent variable is a survival time which is loglogistic distributed. The data used in this study were right censored. Log-logistic regression models for survival data can be expressed by transformation $Y=\ln T$. The parameter of the log-logistic regression models for right censored survival data are estimated with the maximum likelihood method. In this study, the application of log-logistic regression model for survival data is in data of lung cancer patients. Best log-logistic regression model is obtained $y_{i}=1.92458+0.0242393 x_{i 1}+0.639037 \varepsilon_{i}$.
\end{abstract}

Keywords: Regression, right censored data, maximum likelihood.

\begin{abstract}
Abstrak
Analisis survival merupakan analisis yang digunakan untuk mengetahui lama waktu yang dibutuhkan oleh suatu objek untuk dapat bertahan hidup. Waktu tersebut dipengaruhi oleh beberapa faktor yang disebut dengan variabel independen. Salah satu cara untuk mengetahui hubungannya adalah melalui model regresi. Variabel dependen merupakan waktu survival yang berdistribusi log-logistik. Data yang digunakan dalam penelitian ini adalah data tersensor kanan. Model regresi log-logistik untuk data survival dapat dinyatakan dengan transformasi dengan $\mathrm{Y}=\ln \mathrm{T}$. Estimasi parameter dari model regresi loglogistik untuk data tahan hidup tersensor kanan menggunakan metode maksimum likelihood. Penerapan model regresi log-logistik untuk data survival yang digunakan dalam penelitian ini adalah data pasien kanker paru-paru. Berdasarkan olah data yang sudah dilakukan, model regresi log-logistik terbaik $\mathrm{y}_{\mathrm{i}}=1.92458+0.0242393 \mathrm{x}_{\mathrm{i} 1}+0.639037 \varepsilon_{\mathrm{i}}$.
\end{abstract}

Kata-kata kunci: Regresi, Data tersensor kanan, metode maksimum likelihood.

\section{PENDAHULUAN}

Analisis survival adalah analisis yang berfungsi untuk mengetahui ketahanan hidup suatu objek yang diteliti. Variabel yang diperhatikan dalam analisis survival adalah waktu sampai terjadinya kejadian khusus. Kumpulan data yang digunakan dapat berupa data tersensor. Data tersensor adalah hasil pengamatan dari objek yang diteliti pada kurun waktu tertentu dan tidak mengalami kegagalan hingga penelitian berakhir. Analisis survival melibatkan bentuk data time to event atau dapat disebut data survival, yaitu suatu hasil pengamatan yang dilakukan pada kurun waktu tertentu sampai terjadinya suatu kejadian. Kumpulan data yang digunakan dapat berupa data lengkap atau tersensor. 
Analisis survival akan sesuai jika digunakan pada data lengkap. Tetapi, pada kenyataannya terdapat kendala pada suatu penelitian seperti keterbatasan dana dan waktu. Dalam hal ini, diperlukan penyensoran data agar lebih efisien dari segi biaya dan waktu. Jenis penyensoran yang dapat digunakan untuk mempercepat penelitian adalah tersensor kanan dan tersensor kiri. Tersensor kanan terjadi bila objek belum mengalami kegagalan sampai penelitian berakhir, sedangkan tersensor kiri terjadi bila kegagalan pada objek sudah terjadi saat objek masuk dalam pengamatan. Analisis data survival dengan data tersensor diperlukan asumsi tertentu tentang distribusi populasinya.

Beberapa distribusi yang dapat digunakan untuk menggambarkan waktu survival antara lain distribusi eksponensial, distribusi Weibull, distribusi gamma, distribusi log-logistik, dan lain-lain (Lawless, 1982). Dalam penulisan ini, hanya mengkaji fungsi survival berdistribusi log-logistik. Distribusi log-logistik memiliki kelebihan yang tidak dimiliki oleh distribusi lain, yaitu dapat digunakan pada analisis survival penyakit. Waktu tahan hidup tiap individu yang berdistribusi loglogistik dapat dipengaruhi oleh beberapa faktor atau variabel independen. Faktor-faktor tersebut dilihat pada setiap individu saat pengamatan, misalnya umur, jenis kelamin, treatment dan lainnya. Maka, pada penulisan ini akan dikaji ulang tentang analisis survival dengan model regresi pada data tersensor kanan berdistribusi log-logistik.

\section{METODE}

\section{Analisis Survival}

Analisis survival merupakan prosedur statistika untuk keperluan analisis data, dimana data yang digunakan berupa waktu sampai terjadinya suatu kejadian tertentu. Kleinbaum (2005) mengemukakan bahwa ada tiga elemen yang perlu diperhatikan dalam menentukan waktu survival, yaitu titik awal yaitu waktu dimulainya suatu penelitian, kejadian yang menjadi inti dari penelitian, dan ukuran waktu yang digunakan. Misalkan $\mathrm{T}$ adalah variabel acak yang menunjukkan waktu survival maka $\mathrm{T}$ bernilai nonnegatif, $\mathrm{T}>0$.

\section{Kuantitas Dasar Analisis Survival}

Analisis survival ditunjang oleh beberapa kuantitas dasar yaitu sebagai berikut

1. Fungsi Kepadatan Peluang

Fungsi kepadatan peluang adalah peluang kegagalan individu pada suatu interval $(t, t+\Delta t)$ persatuan waktu. Fungsi kepadatan peluang dinyatakan dengan $\mathrm{f}(\mathrm{t})$

$$
\mathrm{f}(\mathrm{t})=\lim _{\Delta t \rightarrow 0} \frac{P(t \leq T \leq(t+\Delta t))}{\Delta t}
$$

2. Fungsi Survival

Fungsi survival adalah peluang suatu individu yang masih dapat bertahan hidup sampai dengan waktu $t$, dimana $t>0$. Fungsi survival dapat dinyatakan sebagai

$\mathrm{S}(\mathrm{t})=\mathrm{P}(\mathrm{T}>\mathrm{t})$

3. Fungsi Hazard

Fungsi hazard adalah rate suatu individu mengalami kegagalan dalam interval waktu t sampai $(t, t+\Delta t)$, jika individu tersebut masih bertahan hidup sampai dengan waktu $t$.

$$
\mathrm{h}(\mathrm{t})=\lim _{\Delta t \rightarrow 0} \frac{P(t \leq T \leq t+\Delta t \mid T>t)}{\Delta t}
$$

\section{Data Tersensor}

Data dikatakan tersensor jika pengamatan waktu tahan hidup hanya sebagian, tidak sampai waktu kejadian. Ada tiga tipe penyensoran yang dapat digunakan, yaitu

1. Sensor Kanan

Dikatakan tersensor kanan pada titik $\mathrm{k}$, apabila nilai observasi yang digunakan $\mathrm{t}$, dan $\mathrm{t} \leq \mathrm{k}$.

2. Sensor Kiri 
Suatu data atau observasi dikatakan tersensor kiri pada titik $\mathrm{k}$, apabila nilai observasi yang digunakan adalah $\mathrm{t}$, dan $\mathrm{t} \geq \mathrm{k}$.

3. Sensor Interval

Sensor interval terjadi ketika hanya diketahui bahwa suatu event yang diinginkan terjadi dalam suatu periode waktu. Data tersensor kiri dan tersensor kanan merupakan kasus khusus dari data tersensor interval.

\section{Distribusi Log-logistik}

Distribusi log-logistik adalah distribusi peluang dari variabel acak yang logaritmanya memiliki distribusi logistik. Suatu variabel acak Y dikatakan memiliki distribusi logistik dengan parameter $(\mu, \sigma)$, jika fungsi kepadatan peluangnya sebagai berikut

$$
\mathrm{f}(\mathrm{y})=\frac{\exp \left(\frac{y-\mu}{\sigma}\right)}{\sigma\left(1+\exp \left(\frac{y-\mu}{\sigma}\right)\right)^{2}}
$$

Variabel acak $\mathrm{T}$ dikatakan mengikuti distribusi log-logistik dengan parameter $\beta$ dan parameter bentuk $\alpha$, jika mempunyai fungsi densitas

$$
\mathrm{f}(\mathrm{t})=\frac{(\beta / \alpha)(t / \alpha)^{\beta-1}}{\left\{1+(t / \alpha)^{\beta}\right\}^{2}}
$$

Fungsi distribusi kumulatif dari distribusi log-logistik adalah

$$
\mathrm{F}(\mathrm{t})=\frac{t^{\beta}}{\alpha^{\beta}+t^{\beta}}
$$

Fungsi survival dari distribusi log-logistik adalah

$$
\mathrm{S}(\mathrm{t})=\frac{1}{1+(t / \alpha)^{\beta}}
$$

Fungsi hazard dari distribusi log-logistik adalah

$$
\mathrm{h}(\mathrm{t})=\frac{(\beta / \alpha)(t / \alpha)^{\beta-1}}{\left\{1+(t / \alpha)^{\beta}\right\}}
$$

\section{Model Regresi Data Survival}

Model regresi digunakan pada analisis survival untuk memodelkan hubungan antara waktu survival sebagai variabel dependen dengan faktor-faktor yang berpengaruh sebagai variabel independen, dengan asumsi bahwa populasi tahan hidup yang diteliti berdistribusi tertentu. Menurut Lawless (1982), persamaan regresi parametrik pada analisis survival dinyatakan dalam model skala, yaitu waktu survival $\mathrm{T}$ ditransformasikan logaritma sehingga menjadi $\mathrm{Y}=\ln \mathrm{T}$, dan diperoleh persamaan regresi berikut

$$
\mathrm{Y}=\ln \mathrm{T}=\mu(\mathrm{x})+\sigma \varepsilon
$$

\section{Metode Maksimum Likelihood}

Metode untuk mengestimasi nilai parameter distribusi dari data dalam fungsi tahan hidup adalah dengan menggunakan metode maksimum likelihood. Misalkan $\mathrm{X}_{1}, \mathrm{X}_{2}, \ldots, \mathrm{X}_{\mathrm{n}}$ adalah variabel acak dari populasi dengan fungsi kepadatan peluang $\mathrm{f}\left(\mathrm{x} \mid \theta_{1}, \theta_{2}, \ldots, \theta_{\mathrm{m}}\right)$, fungsi likelihood didefinisikan dengan

$$
\mathrm{L}\left(\theta_{1}, \theta_{2}, \ldots, \theta_{\mathrm{m}} \mid \mathrm{X}\right)=\prod_{i=1}^{n} \mathrm{f}\left(\mathrm{x}_{\mathrm{i}} \mid \theta_{1}, \theta_{1}, \ldots, \theta_{\mathrm{m}}\right)
$$

Bila fungsi likelihood terdeferensialkan dalam $\theta_{1}, \theta_{2}, \ldots, \theta_{\mathrm{m}}$, maka estimator maksimum likelihood yang mungkin adalah

$$
\frac{\partial}{\partial \theta_{k}} \mathrm{~L}\left(\theta_{1}, \theta_{2}, \ldots, \theta_{\mathrm{m}} \mid \mathrm{X}\right)=0
$$

\section{Uji Anderson Darling}

Misalkan $\mathrm{x}_{1}, \mathrm{x}_{2}, \ldots, \mathrm{x}_{\mathrm{n}}$ adalah data yang akan diuji distribusi, maka uji Anderson Darling dapat diperoleh dengan menggunakan rumus sebagai 


$$
\mathrm{A}=-\mathrm{n}-\frac{1}{n} \sum_{i=1}^{n}[2 i-1]\left[\ln \left(F\left(x_{i}\right)\right)-\ln \left(1-F\left(n_{n-i+1}\right)\right)\right]
$$

Dalam hal ini, pendugaan distribusi yang sesuai dipilih berdasarkan nilai Anderson Darling terkecil. Beberapa distribusi yang dapat digunakan ketika melakukan uji distribusi yaitu Smallest extreme value, Exponensial, Log-logistik, Logistik, Normal, dan Weibull (Lawless, 1982). Distribusi yang memiliki nilai Anderson Darling (AD) terkecil adalah distribusi yang paling cocok atau mendekati variabel respon yang berupa waktu survival.

\section{Uji Signifikansi Parameter}

Uji signifikansi parameter dilakukan setelah diperoleh estimasi model regresi, dilakukan untuk mengetahui variabel independen yang memiliki pengaruh signifikan terhadap model. Pengujian yang dilakukan adalah uji secara simultan yaitu menggunakan uji partial likelihood ratio dan pengujian secara parsial yaitu menggunakan uji Wald.

\section{Tahapan Analisis}

1. Memilih data tahan survival tersensor kanan.

2. Menguji kecocokan data apakah mengikuti distribusi log-logistik.

3. Mengestimasi parameter dengan metode maksimum likelihood.

4. Membentuk model regresi survival.

5. Menguji signifikansi koefisien regresi secara simultan dan parsial.

6. Mendapatkan model regresi terbaik.

\section{HASIL DAN PEMBAHASAN}

\section{Model Regresi pada Data Survival Berdistribusi Log-logistik}

Model regresi waktu survival dibentuk dalam model skala lokasi. Dalam model ini, waktu survival $\mathrm{T}$ ditransformasikan logaritma sehingga menjadi $\mathrm{Y}=\ln \mathrm{T}$ dan diperoleh persamaan regresi

$$
\mathrm{Y}=\ln \mathrm{T}=\mu(\mathrm{x})+\sigma \varepsilon
$$

dengan $\sigma>0$ dan $\varepsilon$ memiliki distribusi logistik.

Diketahui $\mathrm{T}$ adalah variabel acak berdistribusi log-logistik dengan fungsi kepadatan peluag $\mathrm{T}$ yang diberikan oleh $\mathrm{x}$ tertentu. Jika $\mathrm{T}$ ditransformasi menjadi $\mathrm{Y}=\ln \mathrm{T}$, maka diperoleh fungsi kepadatan peluang $\mathrm{Y}$ yang diberikan oleh $\mathrm{x}$ tertentu yang identik dengan fungsi kepdatan peluang distribusi logistik, yaitu

Fungsi distribusi kumulatifnya adalah

$$
\mathrm{f}(\mathrm{y} \mid \mathrm{x})=\frac{\exp \left(\frac{y-\mu(x)}{\sigma}\right)}{\sigma\left(1+\exp \left(\frac{y-\mu(x)}{\sigma}\right)\right)^{2}}
$$

Fungsi survival sebagai berikut

$$
\mathrm{F}(\mathrm{y} \mid \mathrm{x})=1-\frac{1}{1+\exp \left(\frac{y-\mu(x)}{\sigma}\right)}
$$

$$
\mathrm{S}(\mathrm{y} \mid \mathrm{x})=\frac{1}{1+\exp \left(\frac{y-\mu(x)}{\sigma}\right)}
$$

dan fungsi hazard-nya adalah

$$
\mathrm{f}(\mathrm{y} \mid \mathrm{x})=\frac{\exp \left(\frac{y-\mu(x)}{\sigma}\right)}{\sigma\left(1+\exp \left(\frac{y-\mu(x)}{\sigma}\right)\right)^{2}}
$$

Estimasi Parameter pada Data Tersensor Berdistribusi Log-logistik

Fungsi likelihood untuk data tersensor kanan adalah sebagai berikut 


$$
\mathrm{L}=\prod_{i=1}^{n} f\left(t_{i}\right)^{\delta_{i}}\left[S\left(t_{i}\right)\right]^{\left(1-\delta_{i}\right)}
$$

Maka, fungsi likelihood untuk mengestimasi parameter distribusi log-logistik adalah

$$
\mathrm{L}(\alpha, \beta)=\prod_{i=1}^{n}\left[\frac{(\beta / \alpha)\left(t_{i} / \alpha\right)^{\beta-1}}{\left\{1+\left(t_{i} / \alpha\right)^{\beta}\right\}^{2}}\right]^{\delta_{i}}\left[\frac{1}{1+\left(t_{i} / \alpha\right)^{\beta}}\right]^{\left(1-\delta_{i}\right)}
$$

Estimasi parameter distribusi log-logistik dilakukan dengan menurunkan persamaan likelihood di atas terhadap $\alpha$ dan $\beta$, yaitu sebagai berikut

$$
\sum_{i=1}^{n} \delta_{i}-\sum_{i=1}^{n} \frac{\left(\delta_{i}+1\right)\left(t_{i} / \alpha\right)^{\beta} \log \left(t_{i} / \alpha\right)}{1+\left(t_{i} / \alpha\right)^{\beta}}=0
$$

dan

$$
\frac{\sum_{i=1}^{n} \delta_{i}}{\beta}+\sum_{i=1}^{n} \delta_{i} \log \left(t_{i} / \alpha\right)-\sum_{i=1}^{n} \frac{\left(\delta_{i}+1\right)\left(t_{i} / \alpha\right)^{\beta} \log \left(t_{i} / \alpha\right)}{1+\left(t_{i} / \alpha\right)^{\beta}}=0
$$

Karena kedua persamaan tersebut tidak dapat diselesaikan secara langsung, maka diperlukan metode numerik untuk mendapatkan hasil estimasinya.

Fungsi likelihood untuk data tersensor kanan adalah sebagai berikut

$$
\mathrm{L}=\prod_{i=1}^{n} f\left(y_{i}\right)^{\delta_{i}}\left[S\left(y_{i}\right)\right]^{\left(1-\delta_{i}\right)}
$$

Maka, fungsi likelihood untuk mengestimasi parameter distribusi log-logistik adalah

$$
\mathrm{L}(\alpha, \beta)=\prod_{i=1}^{n}\left[\frac{\exp \left(\frac{y_{i}-\mu(x)}{\sigma}\right)}{\sigma\left[1+\left(\frac{y_{i}-\mu(x)}{\sigma}\right)\right]}\right]^{\delta_{i}}\left[\frac{1}{1+\exp \left(\frac{y_{i}-\mu(x)}{\sigma}\right)}\right]^{\left(1-\delta_{i}\right)}
$$

Estimasi parameter model regresi distribusi log-logistik dilakukan dengan menurunkan persamaan likelihood di atas terhadap $\mu$ dan $\sigma$, yaitu sebagai berikut

dan

$$
\sum_{i=1}^{n} \frac{-\delta_{i}}{\sigma}+\sum_{i=1}^{n} \frac{\left(\delta_{i}+1\right)(1 / \sigma) \exp \left(z_{i}\right)}{1+\exp \left(z_{i}\right)}=0
$$

$$
-\frac{1}{\sigma} \sum_{i=1}^{n}\left(\delta_{i}\left(z_{i}\right)\right)-\sum_{i=1}^{n} \frac{\delta_{i}}{\sigma}+\sum_{i=1}^{n} \frac{\left(\delta_{i}+1\right)(1 / \sigma) \exp \left(z_{i}\right)}{1+\exp \left(z_{i}\right)}=0
$$

Karena kedua persamaan tersebut tidak dapat diselesaikan secara langsung, maka diperlukan metode numerik untuk mendapatkan hasil estimasinya.

\section{Contoh Penerapan}

Penerapan dilakukan pada data pasien kanker paru-paru yang diperoleh dari The Statistical Analysis of Failure Time Data. 2nd Edition. 2002. John Wiley \& Sons, Inc. Variabel dependen adalah waktu tahan hidup pasien pasca operasi. Variabel independennya terdiri dari performance status dan umur pasien. Data yang diperoleh dianalisis menggunakan perangkat lunak Minitab 16, dengan langkah-langkahnya sebagai berikut

1. Pengujian Distribusi

Beberapa distribusi yang dapat digunakan untuk melakukan uji distribusi yaitu Smallest extreme value, Exponensial, Log-logistik, Logistik, Normal, dan Weibull. Distribusi yang memiliki nilai Anderson Darling (AD) terkecil adalah distribusi yang paling cocok. Maka, dapat disimpulkan bahwa data mengikuti distribusi log-logistik, karena nilai Anderson Darling terkecil yaitu 0,302 dan p-value $>0.250$. Berdasarkan $p$-value tersebut maka distribusi yang sesuai adalah distribusi log-logistik.

2. Estimasi Parameter

Dengan menggunakan metode maksimum likelihood, didapat nilai $\mu=3.85205$ dan $\sigma=0.66830$.

Sehingga diperoleh nilai dari estimasi parameter dari $\alpha$ dan $\beta$ yaitu sebagai berikut

$$
\begin{gathered}
\alpha=\exp (3.85205)=47.0895 \\
\beta=1 / 0.66830\}=1.49633
\end{gathered}
$$

\section{Model Regresi Data Survival}

Dengan bantuan perangkat lunak Minitab, model regresi data pasien kanker paru-paru dibentuk dengan menginput semua variabel independen yaitu performance status $X_{1}$ dan umur $X_{2}$ ke dalam model regresi, sehingga didapatkan hasil sebagai berikut 
TABEL 1. HASIL REGRESI WAKTU TAHAN HIDUP BERDISTRIBUSI LOG-LOGISTIK

\begin{tabular}{llll}
\hline Variabel & Koefisien & P & Zhitung \\
\hline Intercept & 1.92458 & 0.189 & 1.32 \\
X1 & 0.0242393 & 0.021 & 2.31 \\
X2 & 0.0099162 & 0.672 & 0.42 \\
Scale & 0.639037 & & \\
\hline
\end{tabular}

Model ini menggambarkan hubungan antara waktu survival terhadap performance status dan umur. Model regresinya adalah

$$
\mathrm{t}_{\mathrm{i}}=\exp \left(1.92458+0.0242393 \mathrm{x}_{1 \mathrm{i}}+0.0099162 \mathrm{x}_{2 \mathrm{i}}+0.639037 \varepsilon_{\mathrm{i}}\right)
$$

Dengan menggunakan model $\mathrm{Y}=\ln \mathrm{T}$, persamaannya menjadi

$$
\mathrm{y}_{\mathrm{i}}=1.92458+0.0242393 \mathrm{x}_{1 \mathrm{i}}+0.0099162 \mathrm{x}_{2 \mathrm{i}}+0.639037 \varepsilon_{\mathrm{i}}
$$

4. Uji Signifikansi Parameter

Uji signifikansi parameter dilakukan setelah diperoleh estimasi model regresi. Pengujian yang dilakukan adalah uji secara simultan dan pengujian secara parsial.

a. Uji Signifikansi Parameter Secara Simultan

Hipotesis :

$\mathrm{H}_{0}: \theta_{1}=\theta_{2}=\ldots=\theta_{\mathrm{k}}=0$ untuk semua $\mathrm{k}$, dengan $\mathrm{k}=1,2$

(secara simultan, koefisien regresi tidak signifikan secara statistik)

$\mathrm{H}_{1}: \theta_{\mathrm{k}} \neq 0$ untuk paling sedikit satu $\mathrm{k}$, dengan $\mathrm{k}=1,2$

(secara simultan, koefisien regresi signifikan secara statistik)

Taraf signifikan : $\alpha=5 \%=0.05$

Statistik uji : $\mathrm{G}=-2 \ln \mathrm{L}_{\mathrm{R}} / \mathrm{L}_{\mathrm{f}}=-2(-536.124+517.868)=36.512$

Daerah kritik : $\mathrm{H}_{0}$ ditolak jika $\mathrm{G}>\mathrm{X}_{0.05,2}^{2}$

Keputusan : $\mathrm{H}_{0}$ ditolak karena nilai $\mathrm{G}>\mathrm{X}_{0.05,2}^{2}$ yaitu $36.512>5.99148$

Kesimpulan : Karena $\mathrm{H}_{0}$ ditolak, maka dapat disimpulkan bahwa variabel $\mathrm{X}_{1}, \mathrm{X}_{2}$ berpengaruh dalam model.

b. Uji Signifikansi Parameter Secara Parsial

Berdasarkan output dari perangkat lunak Minitab, diperoleh hasil untuk masing-masing koefisien regresi sebagai berikut

TABEL 2. KOEFISIEN REGRESI DATA SURVIVAL TERSENSOR KANAN

BERDISTRIBUSI LOG-LOGISTIK

\begin{tabular}{llll}
\hline Variabel & Koefisien & P & Zhitung \\
\hline Intercept & 1.92458 & 0.189 & 1.32 \\
X1 & 0.0242393 & 0.021 & 2.31 \\
X2 & 0.0099162 & 0.672 & 0.42 \\
Scale & 0.639037 & & \\
\hline
\end{tabular}

Hipotesis :

$\mathrm{H}_{0}: \theta_{1}=\theta_{2}=\ldots=\theta_{\mathrm{k}}=0$ untuk semua $\mathrm{k}$, dengan $\mathrm{k}=1,2$

(secara parsial, koefisien regresi tidak signifikan secara statistik)

$\mathrm{H}_{1}: \theta_{\mathrm{k}} \neq 0$ untuk paling sedikit satu $\mathrm{k}$, dengan $\mathrm{k}=1,2$

(secara parsial, koefisien regresi signifikan secara statistik)

Taraf signifikan : $\alpha=5 \%=0.05$

Daerah kritik: $\mathrm{H}_{0}$ ditolak jika $p$-value $<5 \%$ atau $\left|\mathrm{Z}_{\text {hitung }}\right|>\mathrm{Z}_{\text {tabel }}$ dimana $\mathrm{Z}_{\text {tabel }}=\mathrm{Z}_{\alpha / 2}$

$\theta_{1}=\left|Z_{\text {hitung }}\right|=2.31, p$-value $=0.021$ dan $\theta_{2}=\left|Z_{\text {hitung }}\right|=0.42$, $p$-value $=0.672$

Keputusan : $\mathrm{H}_{0}$ ditolak pada koefisien yang memiliki $p$-value $<5 \%$ yaitu pada koefisien $\theta_{2}$

Kesimpulan : Dapat disimpulkan bahwa $\theta_{2}$ tidak signifikan dalam model, sedangkan $\theta_{1}$

signifikan dalam model. Oleh karena itu, variabel $\mathrm{X}_{2}$ dikeluarkan dari model.

5. Interpretasi Model Terbaik 
Berdasarkan model terbaik yang diperoleh, maka diketahui faktor yang berpengaruh signifikan terhadap waktu survival adalah variabel performance status $\mathrm{X}_{1}$ dengan nilai signifikansi $p$ value $<0.05$. Maka didapatkan model regresi terbaik untuk data pasien kanker paru-paru yang diperoleh dari The Statistical Analysis of Failure Time Data. 2nd Edition. 2002. John Wiley \& Sons, Inc adalah $\mathrm{y}_{\mathrm{i}}=1.92458+0.0242393 \mathrm{x}_{1 \mathrm{i}}+0.639037 \varepsilon_{\mathrm{i}}$

Model regresi di atas dapat diinterpretasikan bahwa variabel $\mathrm{X}_{1}$ yaitu performance status memiliki pengaruh positif terhadap variabel dependen yaitu waktu tahan hidup pasien kanker paru-paru.

\section{KESIMPULAN DAN SARAN}

\section{Kesimpulan}

1. Model regresi untuk data survival yang berdistribusi log-logistik adalah $Y_{i}=\mu(x)+\sigma \varepsilon_{i}$ dimana $\varepsilon$ mengikuti distribusi logistik.

2. Estimasi parameter yang didapatkan adalah

$$
\begin{aligned}
& \sum_{i=1}^{n} \frac{-\delta_{i}}{\sigma}+\sum_{i=1}^{n} \frac{\left(\delta_{i}+1\right)(1 / \sigma) \exp \left(z_{i}\right)}{1+\exp \left(z_{i}\right)}=0 \\
& \text { dan } \\
& -\frac{1}{\sigma} \sum_{i=1}^{n}\left(\delta_{i}\left(z_{i}\right)\right)-\sum_{i=1}^{n} \frac{\delta_{i}}{\sigma}+\sum_{i=1}^{n} \frac{\left(\delta_{i}+1\right)(1 / \sigma) \exp \left(z_{i}\right)}{1+\exp \left(z_{i}\right)}=0
\end{aligned}
$$

Karena kedua persamaan tersebut tidak dapat diselesaikan secara langsung, maka diperlukan metode numerik untuk mendapatkan hasil estimasinya.

3. Model regresi terbaik untuk data pasien kanker paru-paru yang diperoleh dari The Statistical Analysis of Failure Time Data. 2nd Edition. 2002. John Wiley \& Sons, Inc adalah

$$
\mathrm{y}_{\mathrm{i}}=1.92458+0.0242393 \mathrm{x}_{1 \mathrm{i}}+0.639037 \varepsilon_{\mathrm{i}}
$$

\section{Saran}

Saran dari penulis yaitu, dapat dilakukan pengembangan lebih lanjut tentang model regresi pada data survival dengan distribusi yang lain. Seperti distribusi lognormal, distribusi Weibull, dan lainlain. Selain itu, data survival yang digunakan dapat berupa data tersensor kiri.

\section{UCAPAN TERIMA KASIH}

Terima kasih kepada dosen pembimbing dan seluruh pihak yang telah memberikan bantuan kepada penulis dalam menyelesaikan penelitian ini.

\section{REFERENSI}

Alakus, K., Erilli, N.A. 2001. Confidence Intervals Estimation for Survival Function in Log-logistic Distribution and Proportional Odds Regression Based on Censored Survival Time Data. J Biomet Biostat, 2:116.

Bain, Lee J., Engelhardt, Max. 1991. Introduction to Probability and Mathematical Statistics 2nd ed. California: Duxbury Press.

Burnet, Fraix., Gabaud, Valls. 2014. Surival Data and Regression Models. EAS Publication Series, 66, 125-147.

Kalbfleisch dan Prentice. 2002. The Statistical Analysis of Failure Time Data 2nd ed. Wiley \& Sons, Inc. Canada. 
Klein, John P., Moeschberger, Melvin L. 2003. Survival Analysis Techniques for Censored and Truncated Data 2nd ed. New York: Springer.

Kleinbaum, D.G., Klein, M. 2005. Survival Analysis: A Self-Learning Text 2nd ed. New York: Springer.

Lawless, J.F. 1982. Statistical Model and Methods for Lifetime Data 2nd ed. New Jersey: John Wiley \& Sons.

Sari, Ulfah. 2010. Penggunaan Metode Hazard dalam Menentukan Loyalitas Pengguna Kartu Seluler GSM Prabayar. Tesis. Diterbitkan. Institus Pertanian Bogor: Bogor. 